\title{
Teaching Styles In The Yemeni Science Classroom
}

\author{
Angela Abu-Asba ${ }^{1}$, Hazita Azman ${ }^{2}$, Rosniah Mustaffa ${ }^{3}$ \\ ${ }^{I}$ English Language Department, Sana'a University, Yemen \\ ${ }^{2 \& 3}$ Faculty of Social Sciences and Humanities, Univeristi Kebangsaan Malaysia
}

\begin{abstract}
Traditional teaching approaches used for science in Yemen have remained unchanged over the years. There is a need for change in the teaching of science to keep pace with the changing world. There is a need to provide students with knowledge and educate them on problem solving skills using kinesthetic and tactile teaching/learning styles. Prior to attempting to initiate change, it is necessary to first determine present teaching approaches. Using a mixed research approach, the present study investigated the teaching styles of science teachers in Yemen using a modified version of the perceptual learning style preferences by Peacock (2001): visual, auditory, group, tactile, kinesthetic, and individual. The sample group comprised 50 teachers from the faculty. Data was collected by means of questionnaires, interviews, observations, field notes, and videotaped classroom sessions. The questionnaire data were coded and analyzed using SPSS statistical software while an in-depth interview data was transcribed, organized, coded, categorized, and analyzed. The observations, study notes and videotaped classroom sessions were used to triangulate the findings. The emergent findings of this study suggested that the auditory and visual styles were prevalent among the teachers who adopted lecturer-fronted and chalk-and-talk teaching approaches.
\end{abstract}

Keywords: teaching style, science teaching, preferred teaching style, science learning.

\section{Introduction}

Most scholars acknowledged the lucid and remarkable imprints of Arab and Muslim scholars on contemporary scientific fields (Rowe, 2004; Woods, 2004; Razak \& Abdul Majeed, 1998; Maziak, 2005). They played a very important role in hastening the world scientific renaissance, and continued in the effort of developing human knowledge until it reached a remarkable zenith in the period 900-1200 A.D. During that period, Muslims made significant progress and exceptional achievements in areas such as medicine, agronomy, botany, mathematics, chemistry, and optics, and the works of Muslim scholars were disseminated from Spain to the rest of Europe. Then, the Arab-Islamic scientific inventions started to wane due to the slowing down of broader Islamic scientific study, which has been ascribed by many scholars to the "end of the Muslim mind" (Raziak \& Abdul Majeed, 1998).

The teaching of science in the university seems to have waned. It has been observed that most universities and technical schools in the Arab world adopt an approach in which the teacher is viewed as the center of the teaching and learning process (Badran, 2003). In Yemen, the typical didactic methodology has the teacher standing in front of the students and explaining the subject matter while students listen to him passively; hence, there is little interaction (Mahyoub, 1996). Furthermore, there is little funding for science education at all levels in the Arab world (Segal, 1996; Castillo, 2004). According to Castillo (2004), there is neither a vision nor strategy for science education. It is feared that if the education system remains unchanged, the prospects not only for graduate employment, but worse, for the progress and development of Muslim countries will drop to an abysmal low. This might not only have a disastrous effect on the Arab world but is likely also to have a spillover effect on the rest of the universe. It is a critical time, and science educators must seriously rise to the challenge.

In a survey conducted by Mahyoub (1996), he critiqued the overemphasis on teacher-centered approaches and educational activities, claiming that these neglected the development of critical thinking, problem-solving, capability of inquiry and investigative skills which are characteristics of most trained scientists.

Literature studies showed that teachers in Yemen use traditional methods of teaching science and they consider these traditional methods good (Mahyoub, 1996). This finding is of concern to me, and is what has prompted me to investigate salient issues in the teaching and learning of science in Yemen, particularly as no study has yet investigated this problem. One of the major issues is that the focus of learning science in Yemen has been on acquiring basic knowledge, and that this has failed to lead to scientific application (Mahyoub, 1996). 


\section{Literature Review}

Many authors have done research on teaching and learning styles such as Felder and Silverman (1988), Felder (1993), Tobias (1993), Reid (1995), Felder (1995), Peacock (2001), Zhenhui (2001), Zhang (2007), Vaughn and Baker (2008), Quiamzade and Mugny (2009), Tertemiz (2010), Naimie, Siraj, Piaw, shagholi, and Abuzaid (2010), Hsieh, Jang, Hwang, and Chen (2011), Dinçol, Temel, Oskayc, Erdogan, and Yilmaz (2011), Gilakjani and Ahmadi ( 2011).

Teaching and learning styles are the behaviors or actions that teachers and learners exhibit in the teaching-learning exchange. Teaching behaviors reflect the beliefs and values that teachers hold about the learner's role in the exchange. Learner behaviors provide insights into the ways learners perceive interact with and respond to the environment in which learning occurs (Brown, 2003, p. 3). Teaching style, defined by Butler (1984) encompasses:

A set of attitudes and actions that open formal and informal world of learning for students; it is a subtle force that influences student access to learning, and teaching by establishing perimeters around acceptable learning procedures, processes and products. The powerful force of the teacher's attitude toward students as well as the instructional activities used by the teacher shape the learning/teaching experience, and require of the teacher and student certain mediation abilities and capacities ( ibid: p. 52).

According to Moore (1993, p. 14), there is some indication that teachers choose instructional styles that closely approximate to their own learning preferences. It has also been found that teachers tend to have preferred teaching styles with which they are comfortable and revert to in chaotic situations (Vaughn \& Baker, 2008, p. 239-240). In many respects, the relative matching of instructional styles and learning styles may also have implications for students' achievements. Kuchinskas (1979) cited in Dinçol, Temel, Oskayc, Erdogan, \& Yilmaz (2011) concluded in their study that the instructor's teaching style is one of the most significant factors that influence the learning environment. The learning environment. Teaching styles are the leading factors that shape and assure the success of a highly complex teaching-learning process (Artvinli, 2010).

Grasha (2002) views a teaching style as the continuous and consistent behaviors of teachers in their interactions with students during the teaching-learning process. Some teachers focus on rules, others lecture, some demonstrate, others emphasize memory and some others understanding (Yüksel, 2008, p. 63). Grasha (2002) integrated these different styles into a model which might help to understand the nature of teacherstudent encounters. He presented five teaching styles (five positive preceptor styles): Expert, Formal Authority, Personal Model, Facilitator, and Delegator.

This study adopts Peacock's (2001) model of teaching styles in order to examine the teaching styles of Yemeni teachers in the field of science. A modified version of Reid's (1995) Perceptual Learning Style Preference Questionnaire (PLSPQ) is utilized. The model is categorized into six preferences: 1-visual (these learners prefer seeing things in writing), 2-auditory (prefer listening-hearing words spoken and oral explanations), 3-kinesthetic (prefer active participation in activities), 4-tactile (prefer hands-on work-working with experiments in a laboratory-writing notes or instructions), 5-group (prefer studying with others-group interaction) and 6-individual (prefer studying alone-remember information by themselves) learning styles.

\subsubsection{Previous studies on teaching style}

Felder and Silverman (1988) found that students learning styles can be categorized as seeing and hearing (visual), reflecting and acting (kinesthetic), reasoning logically and intuitively, analyzing and visualizing and lastly, steadily and in fits and starts. On the other side of the coin, teaching methods vary between teachers and lecturers with some who prefer to just lecture, while others prefer to demonstrate or lead students to self-discovery; some emphasize memory and others understanding; while some focus on principles and others on application. Felder and Silverman found that there existed mismatches between the learning styles of most students in a class and the teaching style of the teachers/lecturers: the students may become bored and inattentive in class, do poorly on tests, get discouraged by the courses, or the curriculum. In some cases, they likely change to other curricula or drop out of school. Hence the immediate importance of matching teaching styles to learning styles to accommodate the specific needs of students' learning styles.

Daniel and Yusoff (2005) carried out a survey to examine if there was any mismatch between teaching and learning trends in primary school classrooms. The study found that the teachers involved in the study were enthusiastic about various teaching styles. More than $80 \%$ of the teachers preferred conducting class discussions and brainstorming sessions, $43 \%$ indicated they preferred didactic lecture styles, $81 \%$ said they liked to use creative teaching styles, such as games and role play, and more than $80 \%$ of the teachers stated that they wished to conduct activity-based lessons. The survey also revealed that the majority of learners $(34.7 \%)$ in Selangor seemed to use a partial combination of kinesthetic-audio- visual styles, $19.5 \%$ were apparently auditory learners, $18.1 \%$ appeared to be kinesthetic, $4.1 \%$ indicated that they preferred a combination of kinesthetic-visual styles and $16.1 \%$ indicated a preference for a combination of kinesthetic-auditory styles. Surprisingly, only $4.6 \%$ 
seemed to choose a visual learning style while a mere $0.5 \%$ appeared to use a combination of visual-auditory style of learning.

In Peacock's (2001) study of the learning style preferences of EFL and ESL students, the results suggest that the teaching methods mostly suit auditory learners whereas students prefer kinesthetic learning styles above another.

From the theoretical perspective, much recent research has been devoted to learning styles, with many studies focusing on the effects of culture on students' learning styles (Merifield, 1996). Teaching styles, in contrast, have received little attention. Since learning styles are affected by teaching styles, it is important to investigate teaching styles so that efforts may be made towards enhancing the match between teaching and learning styles. Nevertheless, this work focused on science education teachers' preferences in delivering scientific information.

\section{Research Design}

A mixed research methods were used to investigate teaching style in the Science classroom in Sana'a University, Yemen specifically in the department of Biology.

\subsubsection{Participation and context}

Biology teachers at the Faculty of Science comprised the participants of this study and consisted of 29 males and 21 females between the ages of 24 and 60 years at the time of this study (See Appendix A). Data were drawn from the population using random sampling techniques. Their teaching styles were evaluated and described using the data that was collected.

\subsubsection{Instrument}

The research instruments used in this study comprised a survey questionnaire, interviews, and an observation checklist.

\section{Questionnaire}

The survey questionnaire was adapted from Peacock (2001) and contains two parts. Part one elicits the background information of the biology teachers while part two contained the research items on teaching style preferences. The background information of biology teachers' contains age range, gender, teaching experience, university education and proficiency level in the English language (See Appendix A1). The survey questionnaire was used to extract information to identify the science teacher's teaching styles. The science teachers were directed to respond 12 statements as it applied to their teaching of science based on a five-point Likert-scale comprising always, often, sometimes, rarely and never (See Appendix B). The participants were asked to mark the column that corresponded to their level of agreement. This 12 statements contained in the survey questionnaire covered the Reid's six learning style preferences such as visual, group, tactile, auditory, kinesthetic and individual. The data were processed using a computer and analyzed using Statistical Package for Social Sciences (SPSS). The survey questionnaire items were written in English and Arabic. The English was translated by the researchers into Arabic to ensure participants to fully understand them.

\section{Open-Ended Interviews}

The in-depth interview questions adapted from Peacock (2001) were modified with appropriate questions. The interview was used to obtain data that were used to explore the respondents' views on teaching styles and how science was perceived at the Faculty of Science. To ensure that the interviewed participants understood the questions clearly, the researcher translated the questions from English into Arabic to ensure clarity.

\section{Observation Checklist}

A classroom observation checklist was designed to account for all the related aspects of the present study. The twelve groups in the observation checklist comprise science classroom, science class lesson, teachers' attitudes towards teaching science and science lesson atmosphere. The observation checklist was formulated by the researchers to aid in meeting the study objectives (See Appendix C).

\section{Data Collection Procedures}

Prior data collection, teachers were included in the study after granting the permission requesting for the their participation. The data collection covers a month duration. A modified version of the perceptual learning style preference questionnaire (PLSPQ) was completed by teachers based on their teaching style done over a 30 minute period. Semi-structured interviews were used to collect data from 10 lecturers with each lasting between 30 minutes and 1 hour. Probing questions were asked in an attempt to explore lecturers' 
responses in greater depth. The interview sessions were videotaped and recorded using an audio tape recorder. One of the researchers observed the lecturers as a non-participant observer in the science classrooms teaching and laboratory using the research observation checklist to document relevant information.

\section{Data Analysis Procedures}

Quantitative data collected using a survey questionnaire was coded and analyzed using descriptive and inferential statistics. The SPSS statistical software was used for the descriptive analysis inferential statistics based on frequency $(\%)$, means $(\mu)$ and standard deviations $(\sigma)$. Qualitative data collected from interviews was first transcribed, translated and categorized prior to analysis. All the results were analyzed by categorizing them using teaching style preferences by Peacock (2001) and were presented in Tables and Figures. The teachers' indepth interview data were used to supplement data from the questionnaire and data from classroom observation checklists was also evaluated.

\section{Findings And Discussion}

This section presents and discusses the research findings on teachers' teaching styles at the Faculty of Science in Yemen using data collected via questionnaires, classroom observations and study notes. The results obtained using the modified version questionnaire are presented in Tables 1, 2, 3, 4, 5, and 6 . This questionnaire contains visual ( 2 items, $5 \& 8$ ), auditory ( 2 items, $1 \& 7$ ), tactile ( 2 items, $9 \& 11$ ), kinesthetic ( 2 items, $2 \& 6$ ), group (2items, $3 \& 10$ ) and individual ( 2 items $4 \& 12$ ) respectively. Students provided their learning style preferences by responding to each of the 12 statements as applied to science teaching using a 5-point Likertscale questionnaire. The mean value $(\mu)$ and standard deviation $(\sigma)$ were calculated to obtain the average percentages and the differences between the observed value of the teachers' teaching styles. The discussion of the result and the findings are presented using Table and Figure.

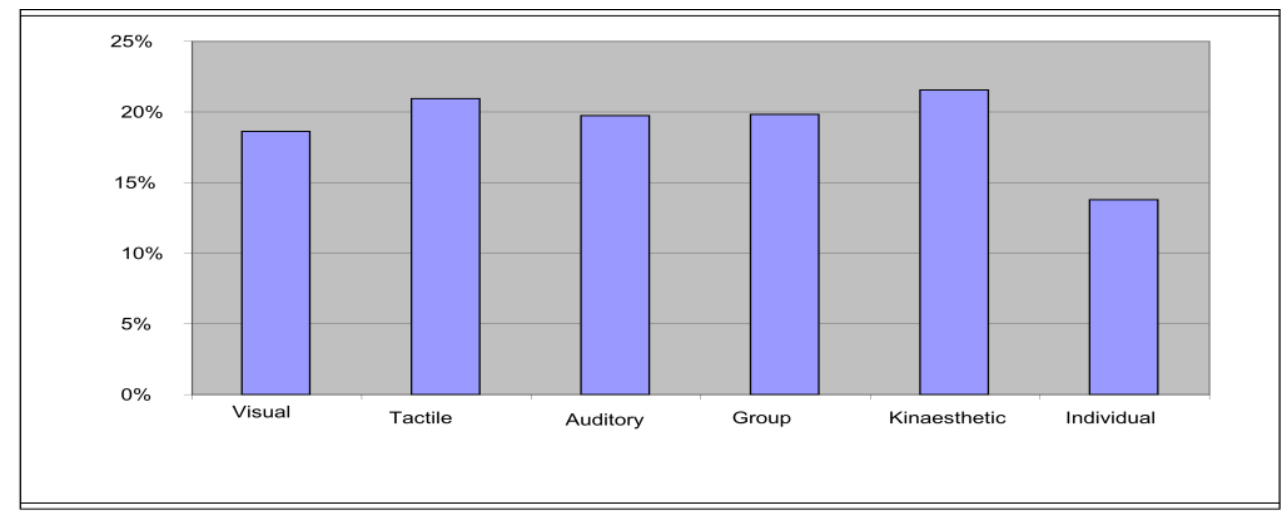

Fig 1: Teachers' Teaching Style

Table 1: Auditory Teaching Style Preferences

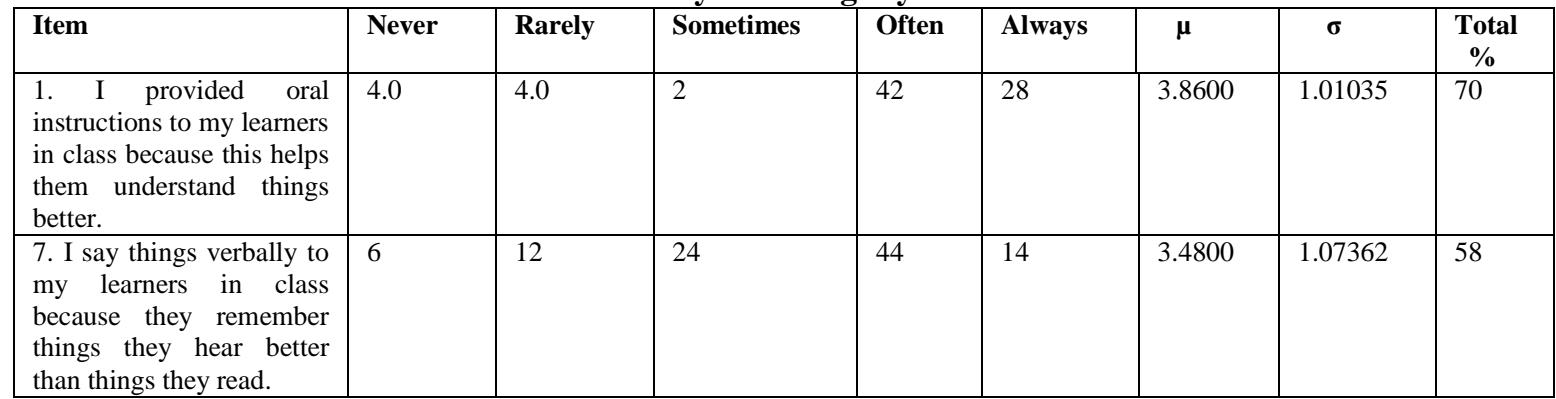

Note: $\mu=$ Mean; $\sigma=$ Standard deviation

The results for auditory teaching style are shown in TABLE 1 . The percentages of teachers who choose always and often for the auditory category were as follows: item no 1 (70\%) and no 7 (58\%) respectively. Figure 1 depicted that the auditory teaching style ranked first. Interview result of two teachers explained why teachers preferred auditory teaching style. Teacher 3 explained that "he say things verbally to his students because this teaching technique helps them to better understand things". Teacher 8 indicated that "the prevailing method in the hall was $70 \%$ but depends on the teacher while $30 \%$ of the student lack other explanatory means such as data show". Teacher 7 mentioned that "this was caused by lack of learning facilities such as LCD, microphones as well as the absence of updates curriculum which makes students to depend on handouts and the 
teacher rather than doing research in the library". This resulted in students having a low knowledge of science and is also reinforced in the classroom observation where the researcher noted that there was inadequate active learning and verbal interaction between the students and teachers. This phenomenon was supported by Social Development Theory of learning postulated by Vygotsky (1978) which asserted the need for a social interaction of students as "more knowledgeable others" (e.g. Teachers, parents, coaches, peers and experts, etc.), Vygotsky concluded that student's cognition is modeled based on social and cultural contexts.

Table 2: Visual Teaching Style Preference

\begin{tabular}{|l|l|l|l|l|l|l|l|l|}
\hline Question Item & Never & Rarely & Sometimes & Often & Always & $\boldsymbol{\mu}$ & $\boldsymbol{\sigma}$ & $\begin{array}{l}\text { Total } \\
\text { \% }\end{array}$ \\
\hline $\begin{array}{l}\text { 5. In class I write things on } \\
\text { the blackboard because my } \\
\text { learners learn better by } \\
\text { reading. }\end{array}$ & 2 & 8 & 28 & 50 & 12 & 4.0200 & 1.02000 & 62 \\
\hline $\begin{array}{l}\text { 8. In class I give handouts } \\
\text { because when my learners } \\
\text { read things, they remember } \\
\text { them better. }\end{array}$ & $4.0 \%$ & 28 & 36 & 16 & 16 & 3.1200 & 1.11831 & 32 \\
\hline
\end{tabular}

Note: $\mu=$ Mean; $\sigma=$ Standard deviation

The results obtained for visual teaching style are shown in TABLE 2 . The percentages of teachers who choose always and often for the visual category comprised: item no $5(62 \%)$ and no $8(32 \%)$ respectively. Figure 1 depicted that visual teaching style ranked second in the overall list of preferred teaching style. An interviewed teachers explained that he preferred the visual teaching style, teacher 4 explained that he preferred to write things on the blackboard because students learned better by reading. At this, students seem to be passive learners in the classroom teaching. Consequently, there is a lack of active learning and verbal interaction between the students and teachers in the science classroom which is an important indication that the teachers chose to teach science using handouts and lecture notes. Based on the researcher's observation from the interviews' data, students memorized the handouts and notes during the examination. This is consistent with Mahbyoub's (1996) finding regarding teachers' preferences for auditory and visual teaching styles. Result from classroom observation revealed that the teacher did not transfer teaching style but mostly explain orally, discussions, reading handouts and using a whiteboard. This implies that science teachers are autocratic and rarely have discussions with students.

Table 3: Kinesthetic Teaching Style Preferences

\begin{tabular}{|l|l|l|l|l|l|l|l|l|}
\hline Question item & Never & Rarely & Sometimes & Often & Always & $\boldsymbol{\mu}$ & $\boldsymbol{\sigma}$ & $\begin{array}{l}\text { Total } \\
\text { \% }\end{array}$ \\
\hline $\begin{array}{l}\text { 2. I prefer to teach by } \\
\text { am my learners doing } \\
\text { something in class. }\end{array}$ & 12 & 8 & 42 & 22 & 16 & 3.2200 & 1.18304 & 38 \\
\hline $\begin{array}{l}\text { 6. I have my learners } \\
\text { do something in class } \\
\text { because they learn } \\
\text { better that way. }\end{array}$ & 2 & 8 & 28 & 50 & 12 & 3.6200 & .87808 & 62 \\
\hline
\end{tabular}

Note: $\mu=$ Mean; $\sigma=$ Standard deviation

TABLE 3 depicted the percentages of teachers who choose always and often as preference or kinesthetic teaching style and are as follows; item no $2(38 \%)$ and no $6(62 \%)$ respectively. The kinesthetic teaching style ranked third in preferred teaching style categories (Figure 1). This indicated that most teachers encourage learning through kinesthetic work though the percentage is not very high (62\%). This is supported by two excerpts from the teacher's interview data. Teacher 3 showed he preferred students to participate in activities, but most students prevent interaction during the classroom teaching. Teacher 5 added that "my students learn better during classroom exercises". It becomes evident that teachers wish their students to participate in activities and involve in classroom work. However, science teachers emphasized that it was difficult to put on the kinesthetic style because of the huge number of the students in the science classrooms, where the teacher obliged to pay only the lecture and examinations. Although, teachers preferred the kinesthetic teaching style, but regrettably do not engage it in the science classroom. This is an important indication that the teachers did not use enough kinesthetic style as observed in class observations. The results reinforced that most teachers used activities relating to movement, constructing things, taking notes or doing projects because of the large number of students (140-150 pupils) in a hall and it was difficult for the teachers to use the kinesthetic teaching style as the style requires that students learn practical experiments and physical activities which is difficult in a classroom. 
Table 4: Group Teaching Style Preferences

\begin{tabular}{|l|l|l|l|l|l|l|l|l|}
\hline Question item & Never & Rarely & Sometimes & Often & Always & $\boldsymbol{\mu}$ & \multicolumn{1}{|c|}{$\begin{array}{c}\text { Total } \\
\%\end{array}$} \\
\hline $\begin{array}{l}\text { 3. I have my learners } \\
\text { study in groups in class } \\
\text { because they learn more } \\
\text { that way. }\end{array}$ & 6 & 22 & 12 & 42 & 18 & 3.4400 & 1.19796 & 60 \\
\hline $\begin{array}{l}\text { 10. I have my learners } \\
\text { work with others in } \\
\text { class because they learn } \\
\text { best that way. }\end{array}$ & 4.0 & 16 & 44 & 28 & 8 & 3.2000 & .94761 \\
\hline
\end{tabular}

Note: $\mu=$ Mean; $\sigma=$ Standard deviation

From the questionnaire results shown in TABLE 4, the teachers indicated a mixed reaction towards group learning by the students. $60 \%$ showed that they held their study in groups because they learn better in that way while $36 \%$ showed that they held their learners work with others in class because they learn best that way. Group teaching style ranked fourth in the overall list of preferred teaching style categories (Figure 1). This result depicted a medium positive response by some teachers but a negative response to group learning from their pupils. This implies that most teachers support the students' preference for learning from group work. This is supported by excerpts from the teachers' interview data. Teacher 15 emphasized that "I prefer students to work in groups because they can learn easily", teacher 6 says that "I do like my students to work with other students because they remember information better". The excerpts showed that students prefer learning in groups because they easily remember when they hashed out with their friends. Based on the questionnaire data, observation data and study notes, result showed that teachers support the students' group work preference. This could be attributed to the general liked to be in groups which is part of the Arab culture. "Collectivism" versus "Individualism" is one of the values that conflicting factors found among Arabs (Hill et al. 1998). In a society in which group cohesiveness is thought to be essential as we found in Yemen, students' de-emphasize self and are concerned about the group. This is not surprising as Yemeni students are taught to demonstrate socially acceptable behaviour without acting out or speaking out. A group's success is rewarded more in this society rather than individual performance. These findings are in agreement with the study by Hofstede (1980) who found that the Arab world is a collectivistic society compared to the western world that practiced individualistic culture.

The importance of Vygotsky's Social Development Theory of Learning (Vygotsky, 1978) was that it highlighted the relevance of communication and social interactions as well as the impact of the social interactions among students with other individuals who are 'more knowledgeable' in order to acquire knowledge. Arab students specifically Yemenis like to be in groups to share feelings with another (Hofstede, 1980). Teachers should exploit this natural inclination of a group sharing in their pedagogy as supported by Vygotsky's theory.

Table 5: Individual Teaching Style Preference

\begin{tabular}{|l|l|l|l|l|l|l|l|l|}
\hline Question item & Never & Rarely & Sometimes & Often & Always & $\boldsymbol{\mu}$ & $\boldsymbol{\sigma}$ & Total\% \\
\hline $\begin{array}{l}\text { 4. I have my learners work } \\
\text { alone in class because when } \\
\text { they work alone, they learn } \\
\text { better. }\end{array}$ & 32 & 16 & 16 & 17 & 2.0 & 2.5800 & 1.31071 & 19 \\
\hline $\begin{array}{l}\text { 12. In class I have my learners } \\
\text { work alone because when they } \\
\text { work alone, they work better. }\end{array}$ & 20 & 48 & 24 & 4.0 & 4.0 & 2.2400 & .95959 & 8 \\
\hline
\end{tabular}

Note: $\mu=$ Mean; $\sigma=$ Standard deviation

The results presented in TABLE 5 showed a very negative response of students learning individually. $19 \%$ of the teachers believed that their pupils would understand better when they work alone in class and $8 \%$ believed that their students are better when they learn alone. Individual teaching style ranked fifth preferred teaching style (Figure 1). The information was supported by teachers interview excerpts where student 8 reported that "I don't prefer students to work alone because they don't learn better". Teacher 1 reported that "some of my students work alone remember information by themselves". This is reinforced in the classroom observation where the researcher found that the science classroom does not include any bodily functions or tasks except for few activities where teachers prefer their students to work in group learning style and rarely individual teaching style. Arab culture does not encourage solidarity and loyalty dependence but rather offers protection and guidance to members. The patriarchal relations are societal rules blended with compassion as the following example represents. A father directs and supports his son/s because he wants them to protect the image of their family and maintain their faith. 
Teaching Styles In The Yemeni Science Classroom

\begin{tabular}{|c|c|c|c|c|c|c|c|c|}
\hline Question item & Never & Rarely & Sometimes & Often & Always & $\mu$ & $\sigma$ & $\begin{array}{c}\text { Tota } \\
\%\end{array}$ \\
\hline $\begin{array}{l}\text { 9. I have my learners } \\
\text { physically } \\
\text { something for in-class } \\
\text { projects because they } \\
\text { learn more that way. }\end{array}$ & 16 & 16 & 60 & 4.0 & 4.0 & 2.6400 & .94242 & 8 \\
\hline $\begin{array}{l}\text { 11.I have my learners } \\
\text { make something for in- } \\
\text { class projects because } \\
\text { they prefer learning that } \\
\text { way. }\end{array}$ & 20 & 48 & 24 & 4.0 & 4.0 & 2.2400 & .95959 & 8 \\
\hline
\end{tabular}

Note: $\mu=$ Mean; $\sigma=$ Standard deviation

TABLE 6 depicted the percentages of teachers who often and always indicate preference for tactile teaching style category comprising item no $9(8 \%)$ and no $11(8 \%)$. The lowest positive inclination was at a tactile style of teaching. Figure 1 indicated that the least preferred teaching style was the tactile learning style and ranked sixth in preferred teaching style. The excerpts from the teachers' interview data explain why this teaching style was preferred; teacher 4 reported that "in science classroom most learners write notes or instructions or make class projects because they prefer learning that way and huge number of students and facilities in the science classroom tries to lecture verbally and most times write on blackboard". This excerpt showed that science teachers believed that they teach better by writing notes. Through classroom observation and study notes, it was noted that the teacher failed to shift from one style to another. Tactile learning style is considered as the best way of learning science besides "hands on" activity whereby the activities assist in the retention of facts, findings and concepts. The researcher's observations showed that the teaching of Biology did not involve experiments and carrying out investigations by students though the basic principles might have been taught. The students are taught the theoretical aspects of the scientific concepts but finds it difficult to follow up with the practical application with the theory. Application of scientific knowledge is supposed to be in the form of investigations of real-life problems and have to be conducted with the guidance of science teachers. This has been noted as a necessary scaffolding process (Raymond, 2000).

\section{Conclusion}

This study tends to investigate the teaching styles of teachers in the Faculty of Science, Sana'a University, Yemen. The results from the questionnaire and observation showed that teachers strongly favored the auditory, visual, kinesthetic, and group teaching styles, but were less inclined to use the tactile and individual teaching styles. The findings revealed that tactile styles such as role-play, handling materials or taking notes are ignored in the teaching of science. It is suggested that tactile, kinesthetic, and group teaching styles are very important styles for science students because there are lots of opportunities for students in a group as they move about and manipulate materials to discover concepts from handling objects or substances. Furthermore, the tactile learning style is considered to be one of the best styles for learning science - apart from the "hands on" part of it, the activities assist in the retention of facts, findings and concepts.

It is clear that there needs to be a change in the teaching and learning process in Yemeni institutions of higher learning. In this paper, it is suggested that a more effective approach would be a balanced teaching style that does not strongly favor any one learning style but rather accommodates multiple learning styles. Different activities should be employed that will meet students' respective learning styles. Nonetheless, it is necessary to first find out what students' preferred ways of learning are in order to determine better teaching strategies in the classroom and to motivate students' participation in class by creating activities related to their learning styles.

The pedagogical implications of this study should be taken into consideration by both science teachers and syllabus designers at Sana'a University. It is hoped that these findings will move policy makers, course designers and developers and classroom teachers at the University of Sana'a as well other Universities in Yemen to review and plan the entire science teaching program in a more effective and realistic manner. Without a sold science teaching program, the state of scientific knowledge would continue to stagnate and the nation would not be able to participate in the scientific endeavors that the rest of the world is actively involved in.

\section{References}

[1] Angela Abu-Asba, Hazita Azman, Rosniah Mustaffa, (2012) Learning styles of Yemeni undergraduate science students. GEMA: Online Journal of Language Studies, 12 (2), 571-591. ISSN 1675-8021

[2] Artvinli, E. (2010). Cografya ögretmenlerinin ögretme stilleri. Elektronic Journal of Social Sciences, 9 (33), $387-408$.

[3] Badran, A. (2003). The Status of Science Teaching in the Gulf Countries. In UNESCO. (Ed.). Connect International Science, Technology \& Environmental Education Newsletter, XXXIII (3-4), 1-6.

[4] Brown, B. L. (2003). Teaching styles vs. Learning Style: Myths and Realities. Eric Publications. Retrieved December 16, 2006 from http://www.calpro-online.org/eric/textonly/docgen.asp?tbl=mr\&ID=117 
[5] Butler,K.A. (1984). Learning and Teaching style: In theory and Practice. Maynard, MA: Gabriel Systems

[6] Castillo, D. D. (2004). The Arab World's Scientific Desert: Once a leader in research, the region now struggles to keep up. Retrieved December 12, 2009 from http://chronicle.com/free/v50/i26/26a03601.htm.

[7] Daniel, E. G. S, \& M. Yusoff. (2003). Teaching and Learning styles in the primary classroom. In Health and Education among the Primary School Pupils in Selangor, Malaysia (Eds.). Centre for Economic Development and Ethics Relations (CEDER), University of Malaya, Kuala Lumpur. (Non-ISI/Non-SCOPUS Cited Publication).

[8] Dinçol, D., Temel, S., Oskayc,O.O., Erdogan,U.I. \& Yilmaz,A. (2011). The effect of matching learning styles with teaching styles on success. Procedia Social and Behavioral Sciences, 15, 854-858.

[9] Dunn, Rita \& Dunn, Kenneth. (1993). Learning Styles/Teaching Styles: Should They....Can they... be Matched? Educational leadership, 36, 21-31.

[10] Felder, R.M. (1993). Reaching the Second Tier: Learning and Teaching Styles in College Science Education. J. College Science Teaching, 23(5), 286-290. http://www4.ncsu.edu/unity/lockers/users/f/felder/public/Papers/Secondtier.html

[11] Felder, R.M., \& Silverman, L.K. (1988). Learning and teaching styles in engineering education Engr. Education, 78 (7). Retrieved July 24, 2009 from From:http://www4.ncsu.edu./unity/lockers/users/f/felder/public/Papers/LS- 1988.pdf

[12] Felder R. M. 1995. Learning and Teaching Styles in Foreign and second Language Education. Foreign language Annals, 28 (1), 21 31.

[13] Gilakjani, A. P \& Ahmadi, S.M. ( 2011). Paper title: The Effect of Visual, Auditory, and Kinaesthetic Learning Styles on Language Teaching. International Conference on Social Science and Humanity, 5, 469-472.

[14] Grasha, A. F. (2002). The dynamics of one-on-one teaching. College Teaching, 50(4), 139-146.

[`15] Hill, C., Loch, K., Straub, D. \& El-Sheshai, K. (1998). A Qualitative Assessment of Arab Culture and Information Technology Transfer. Journal of Global Information Management, 29-38.

[16] Hofstede. G. (1980). Culture's Consequences: international Differences in Work- Related Values. Beverly Hills CA: Sage Publications.

[17] Hsieh, S. W., Jang, Y. R., Hwang, G. and Chen, J. S. (2011). Effects of teaching and learning styles on students' reflection levels for ubiquitous learning. Computers \& Education, 57,1194-1201.

[18] Juris, M. F., Ramos, V.V. \& Castaneda, M. G.G. (2009). Learning and Teaching Crossroads. Institute for Learning Style Journal, 1, $1-19$.

[ 19] Kuchinskas, G. (1979). Whose cognitive style makes the difference? Educational Leadership, 36 (4), 269-271.

[20] Mahyoub, A. A. (1996). Approaches to study process and university classroom environment: the case of pre-service science teachers at the college of education in Sana'a University. Unpublished PhD thesis, University of Pittsburgh, USA.

[21] Maziak. W. (2005). Science in the Arab World: Vision of Glories Beyond. Global Voices of Science, 308 (5727), 1416 - 1418.

[22] Merifield, J. (1996). Examining the language learning strategies used by French adult learners. Birmingham, UK: Aston.

[23] Moore, E. L. S. (1993). An analysis of learning styles, instructional styles and culture among selected accounting students and instructors at the university level. Unpublished PhD thesis, University of Pittsburgh, USA.

[24] Naimie, Z., Siraj,S., Piaw,C.Y., Shagholi, R., \& Abuzaid, R.A. (2010). Do you think your match is made in heaven? Teaching styles/learning styles match and mismatch revisited. Procedia Social and Behavioral Sciences, 2, 349-353.

[25] Peacock, M. (2001). Match or mismatch? Learning styles and teaching styles in EFL. International Journal of Applied Linguistic, $11(1), 1-20$

[26] Portar, S. (2007). Learning styles and science labs. Retrieved April 10, 2011 from http://scienceblogs.com/digitalbio/2007/03/learning_styles and science la.php

[27] Quiamzade, A., Mugny G., Chatard, A.(2009). When teaching style matches students' epistemic (in) dependence: The moderating effect of perceived epistemic gap. European Journal of Psychology of Education, XXIV (3), 361-371.

[28] Raymond, E. (2000). Cognitive Characteristics. Learners with Mild Disabilities Needham Heights, MA: Allyn \& Bacon, A Pearson Education Company.

[29] Razak, A. A. \& Abdul Majeed, A. (1998) Islam: Science and Technology. Malaysia: Institute of Islamic Understanding Malaysia.

[ 3 lefrand_m@yahoo.co.id0] Reid, J. M. (1995). Learning styles in the ESL/EFL classroom. Boston: Heinle \& Heinle Publishers

[31] Rowe, D. (2004). How Islam has kept us out of the 'Dark Ages'. Science and Society. Retrieved July 27, 2006 from File://C:IDocuments\%20and\%20SettingslanglealDesktoplScience\%20and\%20Society.h.

[32] Alain Quiamzade, A., Mugny. G., and Falomir-Pichastor,J.M. (2009). Epistemic constraint and teaching style. European Journal of Psychology of Education, XXIV (2), 181-190.

[33] Salem, G. R. (2001). Instructors' and Students' Antecedents and Contexts: Their Influence on the English Proficiency of College Freshmen. Unpublished Ph.D thesis. Saint Mary's University, Bayombong, Nueva Vizcaya.

[34] Segal, A. (1996). Why Does the Muslim World Lag in Science? The Middle East Foru., 3 (2),1-8. Retrieved September 6, 2006 from http://www.meforum.org/article/306.

[ 35] Soliven, S. (2003). Teaching Styles of High School Physics Teachers. Retrieved October 21, 2003 from www. Hiceducation. org/Edu_2003Proceedings/Samuel\%20R.\%20Soliven.pdf.

[ 36] Tertemiz, N. (2010). Turkish and Finnish trainee elementary teachers' beliefs about the teaching styles of university teaching staff. Social Behaviour and Personality, 38 (7), 941-954.

[ 37] Tobias, S. (1993). They're Not Dumb, They're Different: Stalking the Second Tier. Tuscon Research Corporation. In R. Felder (Eds.). Reading the Second Tier: Learning and teaching styles in College Science Education. ,J.College Science Teaching, 23 (5), 286-290.

[ 38] Vaughn, L. M and Baker, R.C. (2008). Do Different Pairings of Teaching Styles and Learning StylesMake a Difference? Preceptor and Resident Perceptions. Teaching and Learning in Medicine, 20 (3), 239-247.

[39] Vygotsky, L. (1978). Mind in Society: The development of higher psychological process. Cambridge: Harvard University Press.

[40] Woods. M. (2004). Islam, once at forefront of science, fell by wayside: For centuries, Arabic was the language of science and medicine, as English is today. Retrieved June 5, 2010 from http://www.post-gazette.com/pg/04102/299292.stm.

[ 41] Yüksel, G. (2 00 8). Critical thinking and learning /teaching styles. A k a d e m i k A r a s t i r m a la r De r g i s i, (38), 54 73.

[ 42] Zhang, L. (2007). From career personality types to preferences for teachers' teaching styles: A new perspective on style match. Personality and Individual Differences, 43, 1863-1874

[ 43] Zhenhu, R. (2001). Matching teaching styles for ESL/EFL instruction. The internet TESL Journal, 7 (3).

[ 44] Connect: UNESCO International Science, Technology \& Environmental. 